\title{
Diversidade de Phytophthora parasitica isolados de Citrus usando seqüências de nucleotídeos da região ITS-5.8S rDNA
}

\author{
Daniel Dias Rosa ${ }^{1^{*}}$, Marcos Antonio Machado ${ }^{3}$, Maria Luisa Penteado Natividade Targon ${ }^{3}$, Edson Luiz Furtado ${ }^{2}$
}

${ }^{1}$ ESALQ/USP - Depto. de Entomologia, Fitopatologia e Zoologia Agrícola, Setor de Fitopatologia, Av. Pádua Dias, 11, 13418-900, Piracicaba, SP; ${ }^{2}$ Departamento de Produção Vegetal, FCA, Universidade Estadual Paulista, Botucatu, SP, ${ }^{3}$ Centro Avançado de Pesquisa Tecnológica do Agronegócio de Citros Sylvio Moreira, CAPTACSM, Cordeirópolis, São Paulo.

* Autor para correspondência. <danieldr@hotmail.com>

Data de chegada: 27/04/2004. Aceito para publicação em: 26/08/2005.

\begin{abstract}
Rosa, D. D.; Machado, M. A.; Targon, M. L. P. N.; Furtado, E. L. Genotypic diversity among P. parasitica isolates reveled by ITS-5.8S rDNA nucleotide sequences. Summa Phytopathologica, v.32, n.2, p.190-193, 2006.

Phytophthora parasitica is been considered one of the most prevalent citrus soilborn pathogens in Brazil. Fourteen isolates were collected in different region of São Paulo state. Amplification of the ITS region using primers ITS1 and ITS2 produced DNA fragments of 812 to $860 \mathrm{bp}$, that were compared with other sequences obtained to Gene Bank (NCBI). Neighbor-joining analysis, with 1000

bootstrap revealed an average similarity of 99,3 to $100 \%$ between the isolates, and 98,1 to $99,9 \%$ between S. Paulo state isolates and P. nicotianae (= Phytophthora parasitica) obtained from the Gene Bank (gi|8927482). The ITS1 was more conserved than to the ITS2. This is a good tool for quick diagnosis of Phytophthora citrus diseases.
\end{abstract}

Additional keywords: citrus gummosis; ITS, Phylogenetic, Ribosomal DNA.

\section{RESUMO}

Rosa, D. D.; Machado, M. A.; Targon, M. L. P. N.; Furtado, E. L. Diversidade de Phytophthora parasítica isolados de Citrus usando sequiências de nucleotídeos da região ITS-5.8S rDNA. Summa Phytopathologica, v.32, n.2, p.190-193, 2006.

Realizou-se estudo para caracterização e verificação da diversidade genética de Phytophthora parasitica, agente causador da gomose dos citros. Quatorze isolados de Phytophthora parasitica, provenientes do Estado de São Paulo, foram seqüenciados a partir das regiões internas transcritas (ITS1 e ITS2) do gene 5.8S. Obtiveram-se sequiências de $812 \mathrm{pb}$ a $860 \mathrm{pb}$ que foram comparadas com seqüências de outras espécies de Phytophthora spp depositadas no

Palavras-chave adicionais: DNA ribossomal, ITS, Filogenia.
NCBI. Foram feitos estudos filogenéticos, utilizando-se o método "neighbor-joining" com 1000 "bootstrap" e construído o dendrograma mais representativo. Obtiveram-se os resultados de 98,88\% a $100 \%$ de similaridade genética entre os 14 isolados paulistas, e $99,5 \%$ a $98,8 \%$ entre estes e a seqüência de P. nicotianae (gi| 8927482) obtida do GenBank - NCBI.
O gênero Phytophthora, estudado desde o início da fitopatologia (1), abrange patógenos destrutivos a inúmeras espécies de plantas no mundo, tendo sido descritas mais de 60 espécies. Phytophthora parasitica Dastur (= Phytophthora nicotianae var. parasitica Breda de Haan) é uma das muitas estudadas e conhecidas devido aos danos que causa à cultura dos citros. É comum nas regiões subtropicais e, hoje, é uma das espécies mais significativas dentro do complexo de doenças Citrus/Phytophthora. Classificada, taxonomicamente, como pertencente ao reino Chromista, este patógeno é um dos agentes causais da gomose dos citros, que compreende, atualmente, 11 espécies de Phytophothora relacionadas como patógenos agentes causais em plantas cítricas no mundo todo (3).
A classificação taxonômica clássica de Phytophthora parasitica leva em consideração importantes critérios, tais como: forma e natureza do esporângio, forma de inserção do anterídio com o oogônio e seletividade de hospedeiros (9).

As técnicas moleculares vêm se tornando de grande auxilio na taxonomia, através de sequenciamento de regiões conservadas, como aquelas presentes nos nucleotídeos das regiões internas transcritas (ITS1 e ITS2) dos genes ribosomais (rDNA), já foram utilizadas, anteriormente, na taxonomia de Phytophthora (7). A região ITS1-5.8S-ITS2 também tem sido muito utilizada para fins de filogenia por ser conservada dentre espécies e com baixas variações dentro do gênero (2). As seqüências desta região têm sido muito utilizadas na detecção e identificação de 
novas espécies de Phytophthora (5) e outros Oomycotas, como Pythium (8).

Utilizando-se as informações de sequiências da região ITSrDNA, a hipótese da evolução do gênero Phytophthora a partir de ancestrais do gênero Pythium pode ser estudada. O sequenciamento desta região permite, também, a realização de um estudo mais consistente da relação filogenética entre o gênero Phytophthora e os outros Oomycotas. Estudos realizados por Briard et al. (1) na família Pythiaceae, utilizando seqüências do $28 \mathrm{~S}$ rDNA e ITS, demonstram uma divisão em grupos distintos, tais como dos gêneros Phytophthora e Pythium, que corroboram para a hipótese da evolução da família Pythiaceae.

O objetivo deste estudo foi caracterizar molecularmente e analisar as relações filogenéticas existentes entre os isolados de $P$. parasitica obtidos de plantas de citros de diversas regiões produtoras no Estado de São Paulo, juntamente com isolados obtidos de culturas monozoospóricas a partir dos isolados originais.

Foram caracterizados e analisados 14 isolados pertencentes a micoteca do CAPTACSM, Cordeirópolis, São Paulo, Brasil. Os isolados monozoospóricos $(\mathrm{Mz})$ foram obtidos através da diluição seriada de uma suspensão de zoósporos de cada isolado original. A identificação dos isolados monozoospóricos em relação ao isolado original está listada na Tabela 1 .

Todos os isolados foram cultivados em meio de cultura Cenoura-Ágar (3), para onde foram transferidos fragmentos obtidos a partir da cultura permanente, conservados em tubos de ensaio contendo óleo mineral. Os isolados pertencentes à micoteca do Laboratório de fitopatologia do CAPTACSM. A cultura foi incubada a $24^{\circ} \mathrm{C}$, no escuro, por 6 dias, a fim de se obter um crescimento vigoroso do micélio. Após este período, o micélio foi raspado, acondicionado em microtubos de $1,7 \mathrm{ml}$ e, em seguida, foi feita a extração de DNA.

Inicialmente, o micélio foi triturado $(700 \mathrm{mg})$ com auxílio de nitrogênio líquido e o DNA genômico extraído de acordo com protocolo padrão (6). O DNA obtido foi suspenso em $80 \mu \mathrm{lde}$ TE+RNAse e incubado por 4 horas a $37^{\circ} \mathrm{C}$. Em seguida, procedeu-se a reação de pcr utilizando-se os oligonucleotídeos universais para região ribossômica ITS4 e ITS5 (11) para região ITS e gene 5.8S rDNA. O produto de PCR foi sequenciado em um aparelho Applied Biosystems Model 3700 DNA Sequencer, de acordo com instruções do fabricante, utilizando-se os oligonu-

Tabela 1. Isolados e seqüências de Phytophthora spp. e Pythium citrinum estudados.

\begin{tabular}{|c|c|c|c|c|}
\hline Isolados/Sequências & $\operatorname{Acesso}^{(a)}$ & Hospedeiro & Origem & Ano \\
\hline PP01 - Phytophthora parasitica & IAC 01/95 & Citrus spp. & Cordeirópolis /SP/Brasil & 1995 \\
\hline 02 - Phytophthora parasitica & IAC 02/95 & Citrus spp. & Limeira /SP/Brasil & 1995 \\
\hline 04 - Phytophthora parasitica & IAC 04/95 & Citrus spp. & Limeira/SP/ Brasil & 1995 \\
\hline 06 - Phytophthora parasitica & IAC 06/95 & Citrus spp. & Taubaté /SP/ Brasil / & 1995 \\
\hline 07 - Phytophthora parasitica & IAC 07/95 & Citrus spp. & Limeira /SP/Brasil & 1995 \\
\hline 09 - Phytophthora parasitica & IAC 09/95 & Citrus spp. & Limeira /SP/Brasil/ & 1995 \\
\hline 10 - Phytophthora parasitica & IAC $10 / 95$ & Citrus spp. & Taubaté /SP/Brasil/ & 1995 \\
\hline 11 - Phytophthora parasitica & IAC $11 / 95$ & Citrus spp. & Jales /SP/Brasil & 1995 \\
\hline 12 - Phytophthora parasitica & IAC $12 / 95$ & Citrus spp. & Laranjal Paulista/SP/Brasil & 1995 \\
\hline 15 - Phytophthora parasitica & IAC $15 / 95$ & Citrus spp. & Conchal/SP/Brasil & 1995 \\
\hline $16-$ Phytophthora parasitica $-\mathrm{Mz}-15^{(\mathrm{b})}$ & IAC $16 / 95$ & Citrus spp. & Conchal /SP/Brasil & 1995 \\
\hline Phytophthora capsici & gi|8927493| & Piper nigrum & Índia & 1989 \\
\hline Phytophthora cactorum & AF266772 & Rubus idaeus & País de Gales & 1985 \\
\hline Phytophthora nicotinae & AF266776 & - - & Austrália & 一 - \\
\hline Phytophthora brassicae & AF266801 & Brassica chinensis & Reino Unido & 2000 \\
\hline Phytophthora botryosa & AF266784 & - - & - - & 一 - \\
\hline Phytophthora tropicalis & AY208125 & - & China & 2002 \\
\hline Phytophthora bisheria & AY241924 & Fragaria $x$ ananassa & EUA & 2001 \\
\hline Phytophthora arecae & AF266781 & Cocos nucifera & Indonesia & 1991 \\
\hline Phytophthora cajani & AF266765 & Cajanus cajani & India & 1985 \\
\hline Phytophthora cambivora & AF266763 & Rubus idaeus & Escócia & 1985 \\
\hline
\end{tabular}

(a) Número de acesso do GenBank, NCBI, ou dos isolados depositados juntos ao CAPTA Citros Sylvio Moreira

(b) $\mathrm{Mz}$ - isolado que originou os isolados monozoospóricos 
cleotídeos universais ITS2, ITS3, ITS4 e ITS5 (11) para a reação de sequenciamento, sendo obtido no final do sequenciamento quatro sequiências que possuem sobreposição, proveniente de cada oligonucleotideo que possibilitou a obtenção de uma sequiência consenso com qualidade do fragmento da região ITS15,8S rDNA-ITS2 de cada um dos 14 isolados de $P$. parasitica.

Utilizou-se o pacote de programas "Phred/Phrap/Consed" para análise da qualidade das sequências de todos os isolados de $P$. parasitica. Também foram incluídas no estudo as sequiências da região ITS-5.8S rDNA de diversas espécies do gênero Phytophthora presentes no GenBank (Tabela 1). As seqüências foram alinhadas utilizando-se o programa ClustalX1.83 e o resultado deste alinhamento foi utilizado para análise filogenética no programa PAUP*(version 4.0b5a) (10) com análise heurística para utilização no algoritmo de "Neighbor-Joining" com valores de 1000 "bootstrap", para obtenção de um dendrograma que melhor representasse as relações filogenéticas.

As seqüências consensos obtidas, a partir das quatro seqüências amplificadas pelos oligonucleotídeos, variaram de 812 $\mathrm{pb}$ a $860 \mathrm{pb}$, com as regiões ITS1 e ITS2 variando entre 230-239 pb e $420-470$ pb, respectivamente. A região do gene 5.8S rDNA amplificou fragmento de $162 \mathrm{pb}$.

$\mathrm{Na}$ análise da região ITS-5.8S rDNA constatou-se que os 14 isolados de $P$. parasitica, obtidos de diversas áreas do estado de São Paulo, apresentaram de $99,5 \%$ a $98,8 \%$ de similaridade genética em relação ao isolado de P. nicotianae (AF266776), e uma similaridade genética variando de $98,88 \%$ a $100,00 \%$ entre os 14 isolados.

As relações filogenéticas obtidas entre os isolados de $P$. parasitica e as sequiências depositadas no NCBI, foram analisadas pelo método "neighbor-joining" e de parsimonia heurística. A análise demonstrou uma grande proximidade dos isolados de $P$. parasitica obtidos no estado de São Paulo em relação ao isolado de P. nicotiana (AF266776), seguido por P. cactorum (Figura 1). Estes resultados corroboram a hipótese que historicamente o centro de disseminação da $P$. parasitica na citricultura também tenha seu centro de origem a partir da região de limeira, visto que todos os isolados de regiões mais distantes apresentaram grande similaridade com os isolados provenientes desta região, fortalecendo que a distribuição da $P$. parasitica pelo estado de São Paulo foi ocasionada por mudas contaminadas.

$\mathrm{Na}$ análise do dendrograma, obtido na análise filogenética (Figura 1), observa-se a formação de cinco grupos. No grupo 1 ficaram os isolados $03,07,08,09$, e 10, sendo que entre estes a similaridade genética variou de $99,25 \%$ a $100,00 \%$, e uma similaridade genética média de $99,4 \%$ entre estes isolados e o isolado de P. nicotiana (Phytophthora nicotianae var. parasitica) (AF266776).

No grupo 2, ficaram os isolados 15,16 e 17, com uma similaridade genética média de $99,75 \%$ entre eles, sendo que os isolados 16 e 17 são isolados monozoospóricos provenientes do isolado 15. No grupo três ficaram os isolados 12 e 02 com 99,60\% de similaridade genética; no grupo quatro os isolados 04 e 06 , com $99,75 \%$ de similaridade; e no grupo 5 ficaram os isolados PP01, 11 com $99,75 \%$ de similaridade genética.

Neste estudo mostrou-se a existência da variabilidade genética de Phytophthora parasitica e, juntamente, sua filogenia, sendo muitas vezes constatada uma diferença filogenética de 1,2\% entre as seqüências dos isolados de $P$. parasitica. Esta diferen- ça pode, muitas vezes, significar diferenças de subgrupos, como no caso de Rhizoctonia solani, onde diferenças de 1,5\% na sequiência de nucleotídeos da região ITS-5.8S rDNA podem separar os subgrupos GA1 IA e GA1 IB (4).

Constatou-se no presente estudo que a região ITS-5.8S rDNA apresenta-se como uma boa ferramenta para estudos filogenéticos e de taxonomia, como já indicado na literatura. As pequenas variações entre indivíduos de regiões distintas geograficamente e a discriminação entre espécies colocaram a análise de similaridade da sequiência desta região como importante método auxiliar da taxonomia de Phytophthora parasitica e ajudar em analises epidemiológicas deste patógeno, analisando fluxo gênico, sendo necessário estudos mais aprofundados.

\section{REFERÊNCIAS BIBLIOGRÁFICAS}

1. Briand, M.; Dueterte, M.; Rouxel, F. and Brygoo, Y. Ribosomal RNA sequence divergence within the Pythiaceae. Mycology Research. London, v. 99, n.4, p. 1119-1127, 1995.

2. Cooke, D.E.L., Drenth, A., Duncan, J.M., Wagels, G. and Brasier, C.M. A molecular phylogeny of Phytophtora and related Oomycetes. Fungal Genetics and Biology, San Diego, v. 30, n.1, p. 17-32, 2000.

3. Erwin, D.C.; Ribeiro, O.K. Phytophthora diaseses worldwide. St.Paul: APS Press, 1996. 562p.

4. Gonzalez. D.; Carling, D.E.; Kuninaga. S.; Vilgalys. R. and $\mathrm{Cu}-$ beta. M.A. Ribosomal DNA systematics of Ceratobasidium and Thanatephorus with Rhizoctonia anamorphs. Mycologia, New York, v. 93, n. 6, p. 1138-1150, 2001

5. Jung, T.; Nechwatal, J.; Cooke, D.E.L.; Hartmann, G.; Blaschke, M.; Oßwald, W.F.; Duncan, J.M. and Delatour, C. Phytophthora pseudosyringae sp. nov., a new species causing root and collar rot of deciduous tree species in Europe. Mycological Research, London,, v.107, n.7, p.772-789, 2003

6. Kuramae-izioka, E.E. A rapid, easy and high yield protocol for total genomic DNA isolation of Colletotrichum gloeosporioides and Fusarium oxysporum. Revista UNIMAR de Ciência Agrícola., Maringa, v.19, n. 2, p.683-689, 1997.

7. Lee, S.B.; Taylor, J.W. Phylogeny of five fungus-like protoctistan Phytophthora species, inferred from the internal transcribed spacers of ribosomal DNA. Molecular Biology and Evolution, Oxford, v. 9, n. 2, p. 636-653, 1992.

8. Paul, B.; Galland, D.; Bhatnagar, T. and Dulieu, H. A new species of Pythium isolated from the Burgundy region in France. FEMS Microbiology Letters, Delft, v. 158, n.2, p.207-213, 1998.

9. Stamps, D. J., Waterhouse, G. M., Newhook, F. J. \& Hall, G. S. Revised tabular key to the species of Phytophthora. Mycological Papers, Wallingford, v.162, n. 1, p.1-28, 1990.

10. Swofford, D.L. PAUP* Phylogenetic analisys using parsimony: * and other methods:. version 4.0. Sunderland: Sinauer Associates, 2001

11. White, T.J.; Bruns, T.D.; Lee, S. \& Taylor, J.W. Amplification and direct sequencing of fungal ribosomal RNA genes for phylogenetics. In PCR protocols: a guide to methods and applications (eds. Innis, M.A.; Gelfand, D.H.; Sninsky, J.J. \& White, T.J.). San Diego: Academics Press, 1990, pp. 315-322. 


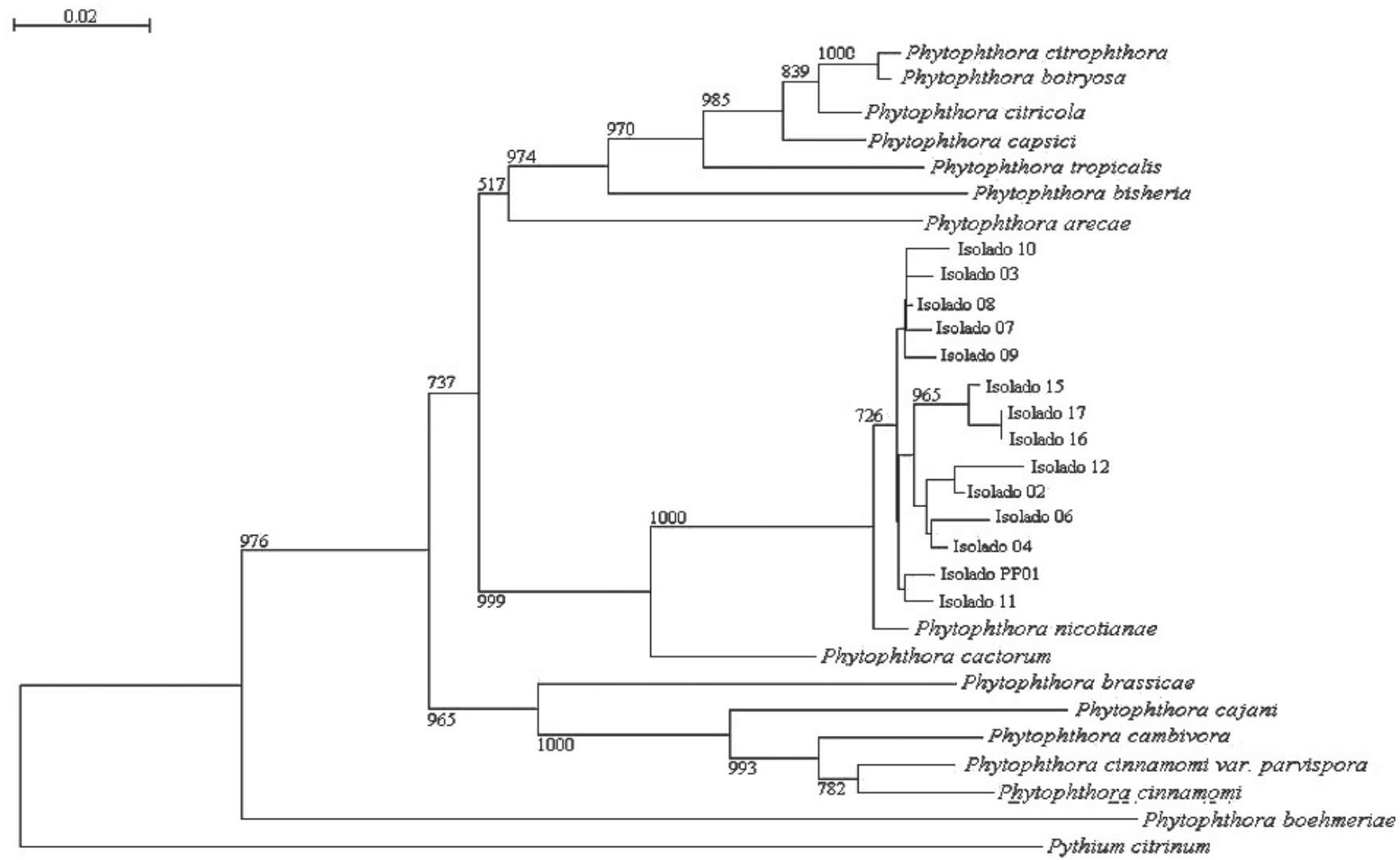

Figura 1. Dendrograma filogenético baseado na análise "Neighbour-joining" da região ITS1-5.8S rDNA-ITS2, construído usando o método de neighbor-joining com base em 1000 réplicas de "bootstrap" O número nas ramificações representa o valor de "bootstrap". O isolado Pythium citrinum foi utilizado como "outgroup". 